\title{
Electrification expansion in the Winterveld region of South Africa in the face of pressure to reduce electricity consumption
}

\author{
C. E. Cloete \& K. R. Kemm \\ Department of Construction Economics, \\ University of Pretoria, South Africa
}

\begin{abstract}
South Africa produces and uses over half of the electricity of the continent of Africa. Over the last decade South Africa has executed a major electrification drive to bring electricity to as many people as possible, and currently the figure stands at over $75 \%$.

However, this electrification figure is in stark contrast to many neighbouring states in which the electrification figure is only 5 to $10 \%$. In Europe many countries have power sharing agreements with neighbouring countries such that in the event of an unforeseen shortfall in electricity supply they can purchase additional supply from neighbours. South Africa is an island in this respect.

South Africa now faces the opposing challenges of cutting back on a rising electricity consumption to protect the national reserve, and forging ahead with an electrification program into currently un-electrified areas, to advance social and economic development.

An interesting case study in this respect is the Winterveld region near Pretoria in which a previously rural farming area, of some 10000 hectares containing about 150000 people is now urbanising rapidly.

The electrification program in the area is facing challenges to electrify rapidly but also to integrate alternative energy sources and strategies wherever possible to try to minimise electricity consumption on the projected growth curve.

Keywords: electrification, Africa, development, social challenge, alternative energy.
\end{abstract}




\section{Introduction}

The concept of sustainability tends to imply that some steady state level of performance has been reached and now the challenge is to sustain that performance in some cost effective, and resource sensitive manner.

This idea of sustainability is somewhat in conflict with the challenge of the rapid and sustained provision of additional energy into a region in which the energy did not exist in the first place.

This is the type of challenge faced in South Africa, and in fact also in other southern African countries. South Africa is a country that exists partly at the forefront of modern first world technology, but also partly in a developing world reality.

There are therefore social and political pressures to be aware of in planning the developmental objective in the state of affairs. While it is at times romantic for tourists to visit South Africa to see the wild animals roaming the untamed spaces, as they have done for thousands of years, the situation has to be viewed differently when considering communities of people who live in twilight areas between the wild open spaces of the animals, and the modern first world cities and high technology areas.

Clearly these people have access to energy, they always have had. However much of their energy consumption tends to be in the form of heat extracted from burning wood which is obtained by chopping down trees in the areas that the first world now wants to protect for reasons of environmental sensitivity.

So when one refers to providing energy to these people it is more a case of substituting modern forms of energy such as electricity, and reducing reliance on traditional forms of energy such as natural wood.

The challenge contains both social and technological factors and so presents itself as a complex scenario for multidisciplinary teams to tackle.

A particular case study is the situation in an area known as the Winterveld, near Pretoria, South Africa.

\section{The Winterveld area}

The Winterveld area is a mixed land use area situated about $40 \mathrm{~km}$ north of Pretoria in the City of Tshwane Metropolitan Municipality (CTMM).

Historically this area of about 10000 hectares in extent was allocated to black farmers in the 1950s. There were no services to the area at the time. Over the years rural people from far afield gravitated towards the metropolitan area around Pretoria and Winterveld farmers started subletting some of their land for residential purposes.

As the numbers of people grew the CTMM authorities decided to convert the southern portion of the Winterveld into residential housing while keeping the northern portion allocated for farming.

The layout of the Winterveld area is shown in Fig 1 [1]. The southern portion of this region is housing, while the northern portion is considered rural. Many farms, of various degrees of sophistication exist. At this stage the farming 


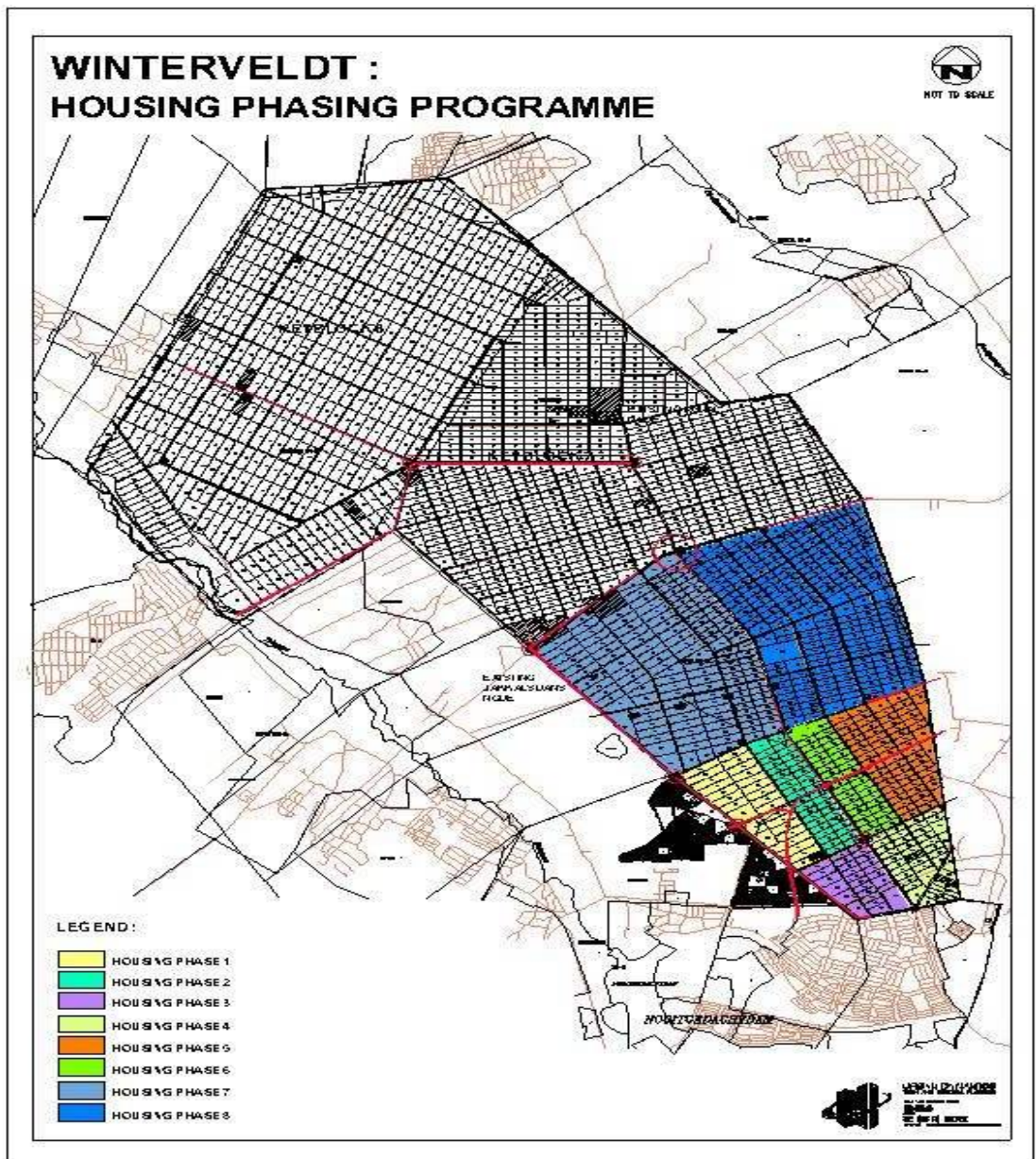

Figure 1: $\quad$ The Winterveld area.

portion is divided into 1881 plots, and since it is intended that farms should continue to develop, three-phase electricity is being supplied to this portion.

The housing portion of the Winterveld is being supplied with conventional single phase 220 Volt electricity. There are 27000 households in the Winterveld. Since the area was originally viewed as rural agricultural, no formal electricity infrastructure was developed initially.

In 2007 the electricity utility Eskom completed installing high mast Apollo lights in the area for security purposes. Initially, 43 Apollo lights were installed, followed by a further 21 . Each mast has six $1 \mathrm{~kW}$ lamps.

Since farm owners had informally sold off, or sublet properties to residential tenants, these properties were not formally legally surveyed and defined as legal entities. This also implied that they could not be legally connected to the municipal electricity supply. 
As a result in 2007 the CTMM and Eskom embarked on a 'normalisation' programme in the Winterveld, which consisted of legally defining properties and then following this with connection to the national electricity grid as municipal funding permitted.

In tandem to this activity the government was building low cost RDP houses in the Winterveld and elsewhere in the country.

A total of 6000 houses were 'normalised' in the lower housing section, plus an additional 3000 RDP houses in the section marked: "RDP Housing Sector" in Fig 1, giving a total of 9000 electrified houses. The budget for this task was R70 million, with Eskom contributing R30 million and CTMM the balance [2].

Each house has been supplied with a 60 Amp circuit breaker, but has also been supplied with a 'pre-load' meter, which is limited in output to 10 Amps. This $10 \mathrm{~A}$ connection is known as a 'lifeline' connection and is viewed as a basic supply. The 60A circuit breaker allows for the homeowner to make extra extensions in the future.

\section{Objectives of the study}

The primary objective of the study was to investigate how to maintain the momentum of the CTMM electrifications programme in the Winterveld, while at the same time abiding by a national call by the electricity utility Eskom for all municipalities to introduce energy measures to reduce electricity consumption by $10 \%$ in the shortest time possible. As the Winterveld is a large area, the cost of providing the infrastructure is high, and the expected electricity usage of the consumers is not great. Thus the provision of a significant amount of electricity infrastructure is not expected to be financially viable for some time to come, and should therefore rather be seen as a social responsibility initiative.

While the primary longer-term objective is undoubtedly to supply the whole area with electricity, for the immediate term the CTMM has an objective of continuing with the provision of electrification infrastructure, and making household connections, in terms of existing development contracts, but at the same time inducing the Winterveld population to use the electricity as sparingly as possible. As a result, alternative, non-electricity forms of energy provision have been proposed. Constraints that formed an envelope to the study include:

- Alternative energy systems must be inexpensive.

- Alternative energy systems must be simple to install and maintain.

- In the case of those systems needing fuel the fuel must be easy to obtain, and be inexpensive.

- Alternative energy systems must either reduce current electricity consumption, or replace potential future consumption.

- The people using the alternative systems are not experienced in their use.

- Systems must not pose a danger to children.

- $\quad$ Systems must be easily reproducible in large numbers. 
Any form of energy carries with it some degree of risk. It is a fundamental concept of economics that there is no risk-free benefit. Clearly also, the provision of energy in various modern forms frees people from the risk that they were exposed to before, for example if people have been burning cow dung or waste plastic-coated paper for cooking, then that air pollution hazard would be eliminated if they used electricity instead.

\section{South African electricity challenge}

South Africa has achieved good economic growth over the past decade [3]. In addition the government has investigated ways of involving more private sector participation in electricity production and reticulation.

A nett effect of these factors is that new electricity generation construction fell behind the rising demand, to the point at which the national reserve capacity is now of the order of $8 \%$ instead of the strategic objective of $15 \%$.

A result of this was that South Africa suddenly found itself subjected to nation-wide rolling blackouts at the end of 2007 and up to about February 2008. This gave the public a huge shock, particularly when the news came out that South Africa's electricity reserve capacity was about half of the design optimum, and so the blackouts could be a feature of life for some years to come [4].

To be fair to Eskom, the midsummer time of the year is traditionally the time when large scale scheduled maintenance is carried out, so reserve capacity is intentionally low. In addition, unanticipated breakdowns made the situation appear to be worse than it was. The result, however, has been that to maintain a more comfortable reserve capacity margin for the coming few years Eskom has to effectively lower the national growth curve in electricity consumption.

The challenge facing the country's institutions, such as municipalities, is to maintain the economic and social growth curves, while decreasing the electricity growth curve. Furthermore, Eskom, backed by government, has put pressure on municipalities to reduce electricity consumption by ten percent, as soon as possible. It is intended that this should be achieved by changing consumption habits, by using lower energy electrical devices, and by implementing alternative energy solutions [5]. If achieved, this would have the longer-term effect of lowering the future electricity consumption curve, of the entire municipality.

\section{Southern African development}

Traditionally there is a distinction made between First World or Developed countries, and Third World countries. The term 'Developing Countries' is usually used to denote some country between First and Third world status. When examining southern Africa one finds that the situation is a group of Third World and Developing World countries.

South Africa itself is an interesting case in that within South Africa the country ranges from advanced first world status to developing world status.

South Africa therefore has advanced development goals, and has been very successful, over the last number of years, in achieving many milestones on the 
various development pathways [6]. Nearly all development requires the consumption of energy, frequently in the form of electricity. Therefore, South Africa's development goals tend to demand an increased use of electricity.

Furthermore, it is in South Africa's political interest to take an interest in the development of other African countries. It is well known that many refugees and general job seekers are legally and illegally migrating to South Africa hoping for a better life. If South Africa helps in the development and stabilisation of their countries, then this action should help stem the flow of job-seekers moving into areas illegally. It is therefore in South Africa's interest if countries of the sub equatorial region develop more rapidly, and therefore by implication use more electricity. This results in the social equation that the faster the general regional development the greater the demand for electricity, which in turn feeds more development.

As part of the mutual development support system of the region, the Southern Africa Power Pool was created. It is useful to be aware of the roles and responsibilities of the SAPP when considering the implications of regional development, and electricity usage.

\subsection{Southern African Power Pool (SAPP)}

Figure 2 indicates the extent of the Southern African Power Pool (SAPP) [7]. The SAPP was established by an Inter-Governmental Memorandum of Understanding (MOU) and signed by Southern African Development Community (SADC) Member Countries in 1995. A revised document was signed on 23 February 2006. An Inter-Utility MOU established the management of the SAPP and a revised document was signed on 25 April 2007.

The generation mix of the SAPP (Figure 3) shows the reliance of the region on coal. But another worrying factor is that the percentage of hydro is so high, and the output of hydro is dependent on rainfall.

The current situation with the SAPP region is:

$\begin{array}{ll}\text { Installed capacity: } & 53,000 \mathrm{MW} \\ \text { Available capacity: } & 45,000 \mathrm{MW} \\ \text { Dependable capacity: } & 41,000 \mathrm{MW}\end{array}$

At the time of formation, the SAPP had over $20 \%$ reserve capacity.

However, in the last 5 years electricity demand in SAPP increased by $15 \%$, which is equivalent to $5112 \mathrm{MW}$. According to SAPP studies, conducted in 2001, if no new investments are made the SADC region would run out of generation surplus capacity by $2007 / 8$ [7]. These predictions are coming true.

The SAPP agreement allows for member states to supply each other with electricity in the event of need. However Fig 4 shows that South Africa possesses by far the largest proportion of the generation capacity of the SAPP, and that there is therefore little potential for South Africa to draw on reserve capacity from neighbouring states in the event of an urgent requirement. 


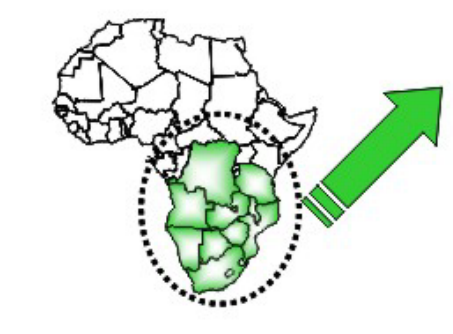

\section{Population: 230 million}

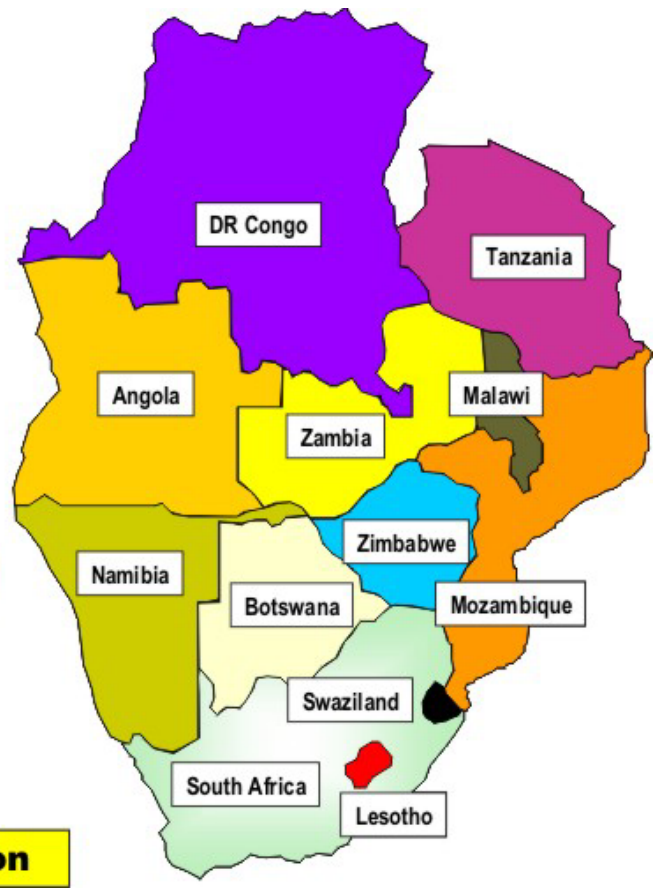

Figure 2: $\quad$ The SAPP region.

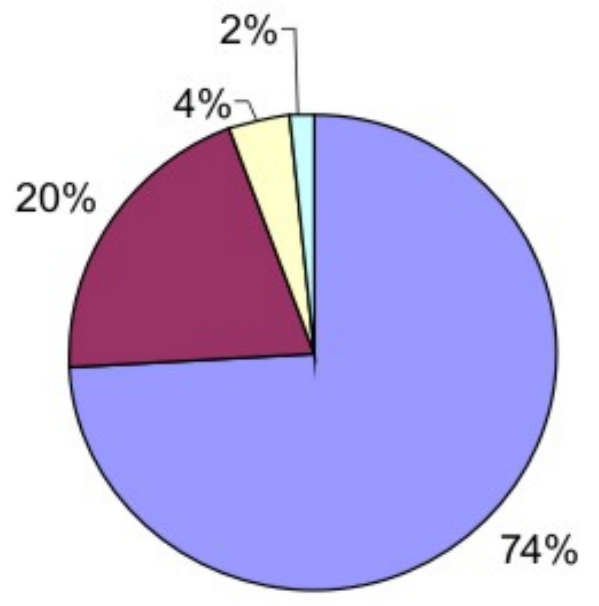

\begin{tabular}{|l|c|}
\hline$\square$ Coal & $74 \%$ \\
$\square$ Nydro & $20 \%$ \\
$\square$ Nuclear & $4 \%$ \\
$2 \%$ \\
\hline
\end{tabular}

Figure 3: Generation mix of SAPP. 


\section{Percentage of SAPP Installed Capacity}

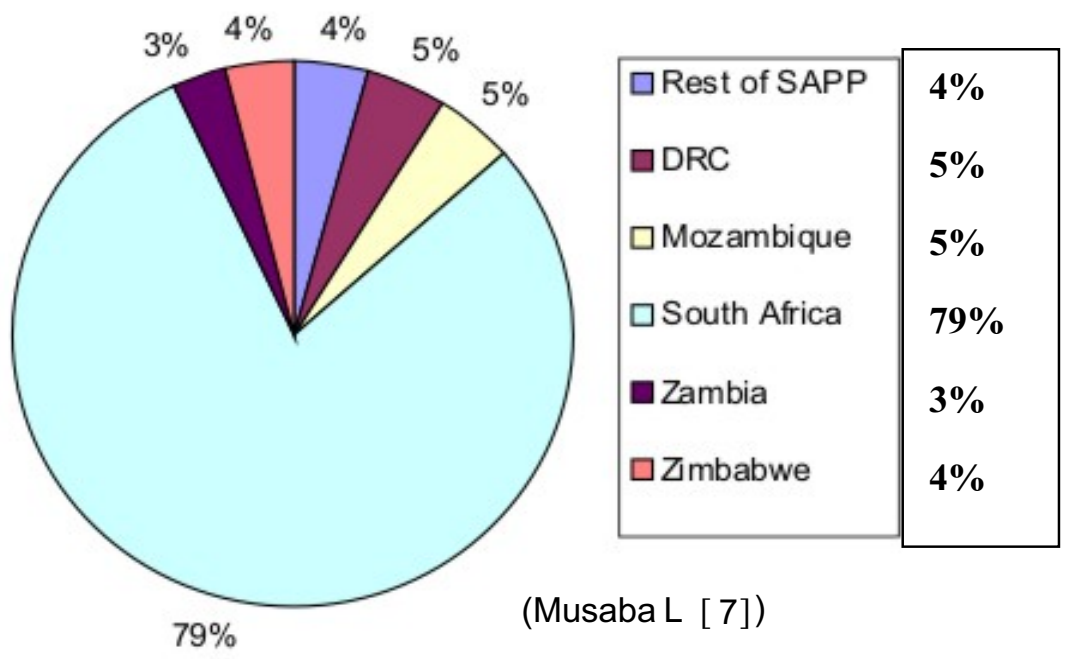

Figure 4: Installed capacity of members of the SAPP.

\section{Non-electrical alternative energy}

\subsection{The approach of the Municipality}

In attempting to change habits in electricity consumption the CTMM authorities embarked on a two pronged campaign: firstly to introduce energy efficient devices wherever possible, such as CFL light bulbs in households, and energy efficient street lights, and secondly to introduce home owners to non-electrical forms of energy [8].

These included ethanol gel cooking stoves. LP gas stoves and lights, and solar thermal water heating systems feeding into an existing electrical geyser [9].

All houses already had electrical connections attached to pre-paid meters. Householders would purchase electricity on coupons and then feed the purchase code into the meter. Thus the use of electricity in the house is very visible, one can watch the digits, recording available power, reducing.

Thus any electricity saving alternative is immediately visible in terms of household budget.

\subsection{Dangerous alternatives}

The rural people, who are moving from a rural lifestyle to urbanisation, as a natural progression of events have moved from using natural wood to using more 
modern energy alternatives such as charcoal and paraffin. While such a move can be seen as a progression it does have its downside [10].

Charcoal is used in cooking stoves, and paraffin is used in paraffin lamps and cooking stoves. These alternatives exhibit major problematic factors in that they can be very dangerous for people [11]. People tend to sleep near charcoal fires and then close windows and doors. The oxygen-starved fire then produces toxic carbon monoxide, which kills the occupants of the dwelling.

In the case of paraffin, the stove is usually placed on the floor, and a pot, which is frequently larger than the stove, is placed on top of it. This results in a situation of a hot liquid on an insecure base with a high centre of mass. The chances of such an assembly being knocked over by a child are great.

In addition, in rural areas, enterprising small business entrepreneurs tend to purchase paraffin in bulk and then to decant it into smaller quantities for resale at a profit. They frequently decant the paraffin into one or two litre cool drink containers, or into containers that look like cool drink containers.

A result of this is that small children find these containers full of liquid and then drink it. A significant number of deaths result. Many children are also hospitalised with chemical pneumonia.

Of the 118000 children who accidentally drink paraffin annually 55000 are hospitalised with chemical pneumonia. Annually 46000 fires are accidentally ignited in homes, which results in R1,3 billion in property damage [12].

\section{Findings}

\subsection{Macro level}

At a macro planning level it was determined that the expansion of the electrification infrastructure program, plus the electrical connection of individual houses will continue at the originally planned rate.

This is due to the fact that service delivery promises were made to the inhabitants of the area; the infrastructure engineering teams are operational and should not be stopped; and the budget was negotiated between various parties and these agreements should not be allowed to lapse.

In addition while housing is being constructed water retaliation is being laid, and roads are being upgraded it makes project planning sense to carry out electrical infrastructural development at the same time.

\subsection{Electricity future}

Currently, houses will continue to be equipped with $60 \mathrm{~A}$ circuit breakers, but supply current will be limited to $10 \mathrm{~A}$. This is to encourage the sense of ownership, and in the future homeowners will be encouraged to improve their personal circumstances by buying extra electrical equipment or building on to their own homes.

As far as current non-electrical energy sources are concerned it is important to move towards a state of affairs in which natural wood, charcoal and liquid paraffin are not used. This has to be a gradual process since these energy sources 
are such an integral part of the existing lifestyle. However, they not only produce significant air pollution, but are also dangerous for people and for property.

\subsection{Non-electrical alternatives}

The non-electrical energy sources introduced by the CTMM received a mixed reaction. The solar water heaters have been most successful and popular. This is due to the fact that they need minimal attention, but most important homeowners can actually see that they save electricity.

As far as ethanol gel is concerned, problems are that after use the residue has to be cleaned out of the stove, and that the fuel has to be purchased and carried home, and then stored in homes with little storage space. When compared to the convenience of electricity these factors are quite significant.

In the case of LP gas, it also has to be carried home in heavy metal pressurise containers. The gas burns with a hot flame, which is dangerous for children. In addition the cost of LP gas changes as the international oil price changes. Early in 2008 LP gas was much cheaper than electricity and this induced many families to try it for cooking and so save on their household energy bills.

But as the oil price rose the cost of LP gas turned out to be about the same as electricity, and so the price advantage fell away, and many families just returned to electricity which is much more convenient.

\subsection{Male and female perceptions}

A social factor, which will change with time, is that there is a difference in male and female perceptions. In many low socio-economic bracket households the woman does the cooking and cleaning but the man makes the financial decisions. Thus, at times, the male head of the household orders that ethanol gel or LP gas be used for cooking, but the women who do the work would opt for electricity if they had a choice.

As these households mature the women will probably gain more influence and so saving the decisions more in favour of electricity.

\subsection{Electrical future}

Therefore, an overall conclusion to be drawn is that electricity will be the preferred energy option in newly electrical areas, and that other non-electrical forms of energy will be used in a transitional manner.

Therefore, for electricity saving the authorities will have to design for low energy options, where ever possible such as in home lighting and street lighting, home heating and in application with electric motors, such as water pumping and other farming and industrial activities that evolve in the area.

\section{References}

[1] Eskom 2007, Eskom Distribution Division, Electrification maps and records, Winterveld Project. 
[2] Leepile, K. J, 2008, CTMM Briefing. Pretoria.

[3] Louw, L., 2008, CEO: Free Market Foundation, Johannesburg. Private Communication

[4] Kemm, K, 2009, Feasibility Study for Sustainable Alternative Energy Technologies for City of Tshwane, Report to the CTMM Jan 2009

[5] Wienand R, 2008, Durban's electricity from landfill gas CDM project, Energize, July 2008

[6] Louw L 2007 Habits of Highly Effective Countries, Lessons for South Africa, Publisher; Law Review Project, SA

[7] Musaba, L, 2007, SAPP planned generation mix Generation mix that mitigates drought Proceedings of the African Utility Week Conference, Cape Town, 28 May - 1 June 2007.

[8] Kemm, K, 2008, Exploration of Societal uptake of Alternative Energy Technologies (The Winterveld Case) Report to the CTMM. June 2008

[9] Utria, Boris E, 2004, Ethanol and Gel fuel: Clean Renewable Cooking Fuels for Poverty Alleviation in Africa. The World Bank. Energy for Sustainable Development, Vol. 8. No. 3. September, 2004

[10] Lloyd P, 2002, The Safety of Paraffin and LPG Appliances for Domestic Use, Journal of Energy in Southern Africa. Vol 13, no 2, May 2002.

[11] Turan, G, 2004. The Poor Man's Fuel: The Continued Use of Paraffin for Domestic Energy Requirements in Low Income Households. PASASA. Environmental Health Conference. February, 2004

[12] de Swardt, C. and Theron, F, 2007, Cape Town African poor: An assessment of poverty manifestations and impact Africanus 37 (1), 21-36. 